\title{
Prevalence of enamel defects in premature children, care and treatment options
}

\section{Introduction}

Prevalence of enamel defects in premature children, care and treatment options. According to the World Health Organization (WHO), ${ }^{1}$ Prematurity can be classified as mild, when the baby is born between the 35th and 36th weeks of gestation; moderate, if the birth occurs between the $31 \mathrm{st}$ and $34^{\text {th }}$ weeks; or extreme, if the gestational age is less than or equal to 30 weeks. ${ }^{2,3}$ The birth of pre-term and/or low birth weight newborns represents a public health problem with increased economic, social, family, and individual costs ${ }^{4}$ Preventive and health promoting measures become necessary in order to improve the quality of life of these children. As such, knowing the risk factors to which they are subject is of fundamental importance for the adoption of such measures. ${ }^{5,6}$

Infants with low birth weight are more susceptible to hypoplasia than normal birth weight, and the most affected primary teeth by hypoplasia were maxillary incisors. ${ }^{4,7}$ These defects occurs due to disorders during amelogenesis. The enamel shows injuries during the development of the teeth, which may appear as hypoplasia of the enamel, diffuse or marked opacity, and hypomineralization of the enamel. Affected patients are usually suffer from poor esthetics, sensitivity in higher levels, some masticatory function issue and lower self-esteem, high caries susceptibility due to irregularities on the tooth surface. Can be improved by treatments such as enamel microabrasion, bleaching, composite resin bonding, and the combination of some or all of these techniques.

\section{Aim}

The aim of this study is to evaluate the perception of the parents and the range of the treatment of premature children.

\section{Material \& method}

Across-section survey written in both English and Arabic languages by researchers were distributed to the parents in Saudi Arabia by social media "twitter, Instagram, WhatsApp application" with three different forms "Yes/No question, closed questions and multiple choices questions" the total response 354 Pearson. The questionnaire consisting of 14 questions were distributed. The demographic details taken from the parents included questions to measure the awareness of the family toward their child white spot lesions and the effect on mastication function and if its effect psychologically to their child.
Volume 10 Issue 5 - 2019

Sara Alshammery, Mais Alomran, Noura Alturki

Department of Restorative Dentistry \& Endodontics, Riyadh Elm University, Saudi Arabia

Correspondence: Sara Alshammery, Department of Restorative Dentistry \& Endodontics, Riyadh Elm University, Saudi Arabia, Email sara@riyadh.edu.sa

Received: September 14, 2019 | Published: September 24, 2019

\section{Results}

A total of (354) completed the questionnaire, the majority of parents responded were mothers $(95.7 \%)$ and $(4.3 \%)$ fathers, with (75.8\%) of high level of education, $(81.1 \%)$ live in Central region of Saudi Arabia ,(42.1\%) have 3-4 children's and (37.2) have 5 and more of children's .

$(67.1 \%)$ have never noticed any white spots on their children's anterior teeth while $(32.9 \%)$ they notice them, we took parents opinion about finding difference between white and dark spots and we found the majority $(84.3 \%)$ notice a difference but $(15.7 \%)$ do not find any difference between them. $(88.3 \%)$ of the parents deny if there is any problem during food mastication. (71.7\%) of parent's didn't notice with their children any sensitive to cold water or sugary food and $(28.3 \%)$ of children get sensitive to them.

To measure the effect of the present of the white spot lesion in children teeth $(86.8 \%)$ of the parent's agree it's not effect on selfconfidant while $(13.2 \%)$ they have a self-confidant effected. We asked the parents about taking children to the dentist to diagnose the problem and we found more than half $(58.8 \%)$ ask the dentist about the treatment and $(43.7 \%)$ of them have solved their condition by dentist and $(56.3 \%)$ have not solved their problem (Figure 1-4).

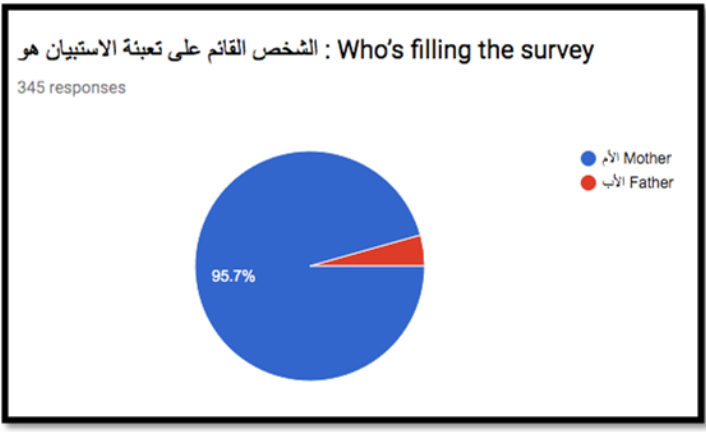

Figure I Who's filling survey. 


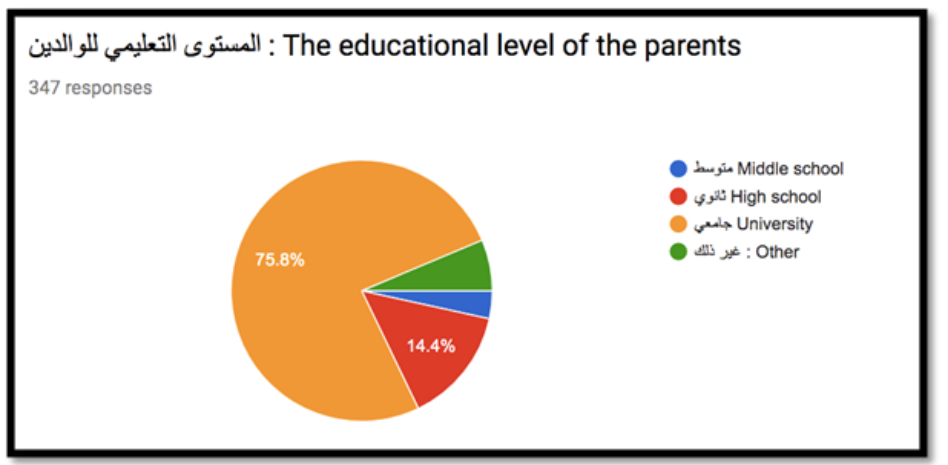

Figure 2 The educational level of the parents.

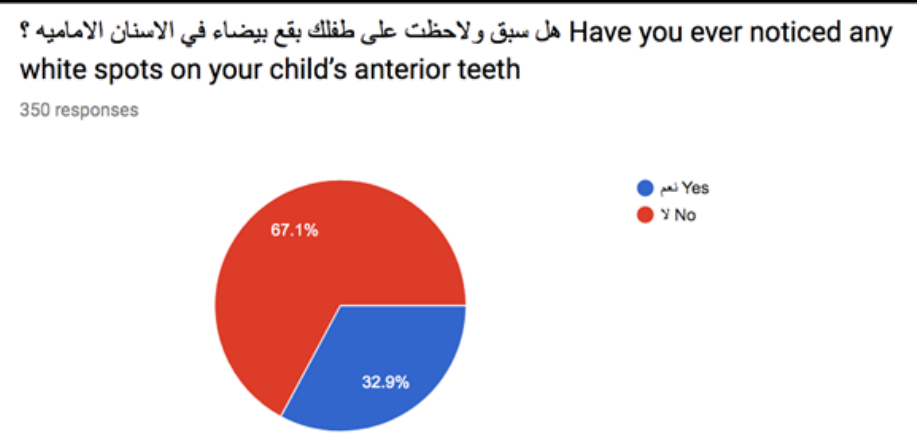

Figure 3 Have you ever noticed any white spots on your child's anterior birth.

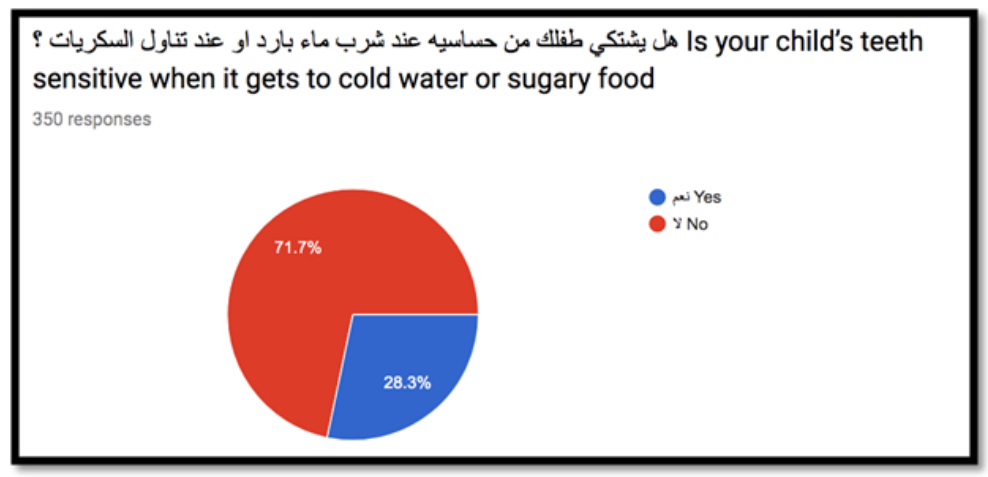

Figure $\mathbf{4}$ Is your child's teeth sensitive when it gets to cold water or sugary food.

\section{Discussion}

In present study, we evaluated the prevalence of enamel defects in pre-mature children and how it's effect them functionally or esthetically and perception of their parents. Prematurity has been described as first causes for the appearance of enamel defects; the etiological factors for these problems are multiple. ${ }^{4,6,8}$ Attitude of participants revealed that $(67.1 \%)$ have never noticed any white spots on their children's anterior teeth and (32.9\%) did notice them earlier Studies revealed that parents perception is uncommon in developing countries.

When questioned about child's teeth sensitivity when it gets to cold water or sugary food, we found that $71.7 \%$ do not suffer while $28.3 \%$ have sensitivity problems, according to several studies a cavity makes a tooth sensitive to cold, hot, or sweets but it's often not the same type of sensitivity that adults experience. ${ }^{2-7}$
Children rarely have the more sensitive root of the tooth exposed, when children have sensitivity, there is usually a definite cause for it. ${ }^{4,7}$ When we asked about white spots effect on child's self confidant, there was $86.8 \%$ of children who are not affected while $13.2 \%$ they are affected, as showing in several studies children can be victim to low self esteem due to their affected teeth, The children with the imperfections could also be embarrassed in front of their friends to smile, the appearance of the teeth can very easily isolate children, and make them reluctant to join in social activities in school. ${ }^{2,6,9,10}$ About asking the parents of visiting a dentist to diagnose the problem $58.8 \%$ of them confirm that they did and $41.2 \%$ did not visit any dentist, A dental check up is important to solve any dental problem in the early stage and as recommended every 6 months.

According to evaluating the parent's knowledge we asked them if they find a difference between white and dark spots, $84.3 \%$ could recognize a difference and it could be related to the educational level which was $75.8 \%$ university educational level. 


\section{Conclusion}

The current study assessed the knowledge and care of the parents about the white spots lesions in their children's teeth, and its shows the good knowledge and willingness to do the ideal treatment.

\section{Funding details}

None.

\section{Acknowledgments}

None.

\section{Conflict of interest}

The authors declare that there is no conflict of interest.

\section{References}

1. World Health Organization. International Statistical Classification of Diseases and Related Health Problems. Geneva: WHO; 1999.

2. Chaves AMB, Rosenblatt A, Oliveira OF. Enamel defects and its relation to life course events in primary dentition of Brazilian children: a longitudinal study. Community Dent Health. 2007;24(1):31-36.

3. Cruvinel VR, Gravina DB, Azevedo TD, et al. Prevalence of dental caries and caries-related risk factors in premature and term children. Braz Oral Res. 2010;24(3):329-335.
4. Chen CF, Chun Hu JC, Estrella MR, et al. Assessment of Restorative Treatment of Patients with Amelogenesis Imperfecta. Pediatr Dent. 2013;35(4):337-342.

5. Federation Dentaire Internationale. Commission on Oral Health, Research and Epidemiology A review of the developmental defects of enamel index (DDE index). Commission on Oral Health, Research \& Epidemiology. Report of an FDI Working Group. Int Dent J. 1992;42(6):411-426.

6. Lai PY, Seow WK, Tudehope DI, et al. Enamel hypoplasia and dental caries in very-low birthweight children: a casecontrolled, longitudinal study. Pediatr Dent. 1997;19(1):42-49.

7. Fearne JM, Bryan EM, Elliman AM, et al. Enamel defects in the primary dentition of children born weighing less than 2000g. Br Dent J. 1990;168(11):433-437.

8. Aine L, Backström MC, Mäki R, et al. Enamel defects in primary and permanent teeth of children born prematurely. J Oral Pathol Med. 2000;29(8):403-409.

9. Cruvinel VR, Gravina DB, Azevedo TD, et al. Prevalence of enamel defects and associated risk factors in both dentitions in preterm and full term born children. J Appl Oral Sci. 2012;20(3):310-317.

10. Drummond BK, Ryan S, O'Sullivan EA, et al. Enamel defects of the primary dentition and osteopenia of prematurity. Pediatr Dent. 1992;14(2):119-121. 